\title{
ECOLOGIA ALIMENTAR DE GONIOPSIS CRUENTATA (LATREILLE, 1830) (DECAPODA, GRAPSIDAE): UMA ABORDAGEM COM O USO DE ISÓTOPOS ESTÁVEIS
}

\author{
Vedolin, M.C.. ${ }^{1,}$; Petti, M.A.V. ${ }^{1}$ \& Figueira, R.C.L. ${ }^{1}$ \\ ${ }^{1}$ Instituto Oceanográfico, USP, São Paulo, SP, Brasil. \\ *Autor correspondente: ma.vedolin@gmail.com
}

Goniopsis cruentata (Decapoda, Grapsidae) é uma espécie comum nos manguezais brasileiros e possui grande importância ecológica, uma vez que atua como consumidor primário e secundário nesses ambientes. O conhecimento sobre a variedade de alimentos e preferências de um organismo é fundamental para o entendimento de sua ecologia e papel funcional no ecossistema. Análises de conteúdo estomacal e isótopos estáveis são ferramentas complementares para obtenção de informações sobre o comportamento alimentar do organismo. Assim, este estudo teve como objetivo caracterizar a dieta natural da espécie por meio da identificação dos itens alimentares e relacionar sua assimilação pela quantificação das frações de $\delta^{13} \mathrm{C}$ e $\delta^{15} \mathrm{~N}$ em tecido muscular, conteúdo estomacal, folhas e sedimento. Os exemplares $(n=153)$ foram coletados em duas regiões do litoral do estado de São Paulo, nas diferentes estações do ano. Amostras de sedimento superficial e de folhas em diferentes estágios de maturação (jovens, maduras e senescentes) também foram coletadas. Em laboratório, os tecidos foram retirados e o conteúdo estomacal foi descrito. As amostras de tecido muscular e de conteúdo estomacal foram separadas de acordo com o local, sexo e estação do ano, caracterizando um "pool". As razões isotópicas de $\mathrm{C}$ e $\mathrm{N}$ foram realizadas em um espectrômetro de massa Elemental Analyser - Isotope Ratio Mass Spectrometer. Em ambos os locais, o item de maior ocorrência foi sedimento, seguido de fragmentos vegetais. Fragmentos calcáreos, estruturas de organismos e grãos de quartzo também foram encontrados. Este resultado está de acordo com a literatura, que considera a espécie generalista por explorar todos os itens disponíveis no manguezal. Os valores das razões isotópicas de $\delta^{13} \mathrm{C}$ foram menores no conteúdo ingerido em relação ao assimilado, já para valores de $\delta^{15} \mathrm{~N}$ ocorreu o inverso. Essas diferenças podem ser resultado de processos metabólicos que envolvem a incorporação dos isótopos. Embora folhas de mangue sejam consideradas de baixo valor nutricional em termos de $\mathrm{N}$, as folhas senescentes parecem ser uma possível fonte em ambas as regiões, enquanto o sedimento atua como uma possível fonte de C. Este estudo confirma o papel dominante desses itens na dieta de G. cruentata, mas investigações sobre os mecanismos de assimilação desses alimentos de baixa qualidade nessas regiões são necessárias a fim de compreender as interações da espécie com estes ambientes, onde há abundância e diversidade de grapsídeos.

Palavras-chave: conteúdo estomacal, crustáceos, isótopos estáveis, manguezal. 